\title{
Stem cell treatment for avascular necrosis of the femoral head: current perspectives
}

This article was published in the following Dove Press journal:

Stem Cells and Cloning: Advances and Applications

9 April 2014

Number of times this article has been viewed

\author{
Matthew T Houdek' \\ Cody CWyles ${ }^{2}$ \\ John R Martin' \\ Rafael J Sierra' \\ 'Department of Orthopedic Surgery, \\ ${ }^{2}$ School of Medicine, Mayo Clinic, \\ Rochester, MN, USA
}

\begin{abstract}
Avascular necrosis (AVN) of the femoral head is a progressive disease that predominantly affects younger patients. Although the exact pathophysiology of AVN has yet to be elucidated, the disease is characterized by a vascular insult to the blood supply of the femoral head, which can lead to collapse of the femoral head and subsequent degenerative changes. If AVN is diagnosed in the early stages of the disease, it may be possible to attempt surgical procedures which preserve the hip joint, including decompression of the femoral head augmented with concentrated bone marrow. The use of autologous stem cells has shown promise in halting the progression of AVN of the femoral head, and subsequently preventing young patients from undergoing total hip arthroplasty. The purpose of this study was to review the current use of stem cells for the treatment of AVN of the femoral head.
\end{abstract}

Keywords: avascular necrosis, femoral head, osteonecrosis, stem cells, concentrated bone marrow

\section{Introduction}

Avascular necrosis (AVN, also know as osteonecrosis) of the femoral head occurs when the cells of the trabecular bone spontaneously die, leading to fracture. ${ }^{1}$ Depending on the amount of femoral head involved, collapse of the articular surface will occur as the disease advances. ${ }^{1,2}$ In the USA, this occurs in 10,000-20,000 adults every year, typically between the ages of 20 and 60 years. ${ }^{1,3,4}$ Once collapse of the femoral head occurs in these patients, severe pain ensues, and the disease course rarely regresses..$^{5-8}$ The primary therapeutic strategy by which these patients experience pain relief is total hip arthroplasty (THA), but at a younger age than in patients undergoing THA for degenerative arthritis. ${ }^{9-11}$

\section{Pathophysiology of AVN}

The pathophysiology of AVN remains unclear despite many attempts to provide a theoretical model. ${ }^{12,13}$ However, there are several recognized conditions and environmental insults that can predispose patients to AVN (Table 1). Although these factors may increase a patient's risk for developing AVN, others propose that the disease results from a clotting disorder or genetic abnormality that leads to vascular compromise. ${ }^{14}$ Another working hypothesis asserts that the cell death is due to increased intramedullary pressure in the femoral head, leading to decreased blood flow and cell death via a mechanism similar to compartment syndrome following a traumatic injury. ${ }^{15}$

Often an underlying cause cannot be determined. However, these idiopathic cases may actually be attributable to clotting abnormalities or collagen mutations. ${ }^{14,16}$
Correspondence: Rafael J Sierra Department of Orthopedic Surgery, Mayo Clinic, 200 First St SW, Rochester, MN 55905, USA

Tel +I 50728425 II

Email sierra.rafael@mayo.edu 
Table I Risk factors for avascular necrosis of the femoral head

\begin{tabular}{ll}
\hline Traumatic/direct injury & Nontraumatic \\
\hline - Femoral neck/head fracture & - Corticosteroid use \\
- Hip dislocation & - Alcohol abuse \\
- Slipped capital femoral & - Idiopathic \\
epiphysis & - Sickle cell disease \\
& - Caisson disease \\
- Systemic lupus erythematosus & - Cushing's disease \\
& - Organ transplantation \\
& - Prior radiation therapy \\
& - Smoking \\
& - Pregnancy \\
- Chronic pancreatitis & - Coagulopathy \\
& - Chronic renal failure \\
- Lipid disorders
\end{tabular}

Jones et al found that approximately $82 \%$ of patients in their study had at least one coagulation factor abnormality. ${ }^{14}$ Similarly, Liu et al noted that a COL2A1 gene mutation in certain families predisposed to development of AVN. ${ }^{16}$

\section{Diagnosis}

Avascular necrosis tends to affect patients aged $20-40$ years, with the average age at presentation being 38 years. ${ }^{3,17,18}$ Symptoms can vary widely, depending on the stage at presentation. In the earlier stages of AVN, patients may note an insidious onset of pain, without a clear cause or inciting event, and will often have a normal range of motion; however, this can be limited by pain, especially with internal rotation of the hip. With progression of the disease, this insidious groin discomfort may be followed by a sudden onset of severe pain. An event of this nature often signals collapse and fracture of the femoral head, leading to end-stage degenerative changes. Development of late-stage disease is typically marked by increasing mechanical symptoms, which include a decreased and painful range of motion, a Trendelenburg sign, crepitus, and catching of the femoral head.

AVN is usually diagnosed on radiologic imaging. Early-stage disease normally requires high-resolution, threedimensional imaging such as magnetic resonance imaging (MRI) or computed tomography; however, late-stage disease can be readily apparent on plain radiographs. The features of AVN on imaging are important because accurate staging of the disease is essential in order to be able to treat each patient appropriately. Several classification schemes can be used to determine the clinical stage $;{ }^{19,20}$ however, we use the Steinberg classification (Table 2) because we feel it to be the most complete. ${ }^{21}$ If AVN is identified during the early stages
Table 2 Steinberg classification ${ }^{21}$ for avascular necrosis of the femoral head

\begin{tabular}{ll}
\hline Stage & \\
\hline 0 & - No symptoms \\
& - Normal X-ray \\
& - MRI nondiagnostic \\
- Mild pain in the affected hip & - Pain with internal rotation \\
& - Normal X-ray \\
& - MRI diagnostic \\
& - Worsening or persistent pain \\
& - Increased sclerosis or cysts in the femoral head \\
3 & - Subchondral collapse producing a crescent sign \\
4 & - Flattening of the femoral head \\
5 & - Normal joint space \\
6 & - Joint space narrowing with/without femoral head \\
& - Advanced degenerative changes \\
\hline
\end{tabular}

Abbreviation: MRI, magnetic resonance imaging.

prior to collapse of the subchondral bone (stage 0-2), the joint is amenable to salvage by a variety of hip preservation techniques. However, if the disease has progressed to stage 3 or greater, THA is frequently the only durable option for pain relief and restoration of function.

\section{Stem cell therapies}

Spontaneous regression of $\mathrm{AVN}$ is rare, with the vast majority of untreated patients progressing to THA..$^{5,711}$ It is thought that, in patients with AVN, there is an insufficient supply of progenitor cells located in the femoral head and proximal femur to remodel the area of necrosis. ${ }^{22}$ Although options to halt the progression of AVN are available (core decompression, osteotomy, medical treatments), the results have been disappointing, with up to $40 \%$ of patients progressing to THA. ${ }^{15}$ Since progenitor cells may be lacking in the lesioned area, newer treatment modalities have been developed to introduce stem cells to the areas of necrosis in an attempt to prevent fracture and collapse by restoring the architecture of the femoral head.

In 2002, Hernigou and Beaujean first described a technique for injecting mesenchymal stem cells combined with standard core decompression to introduce biologics into an area of necrosis. ${ }^{23}$ In this study of 189 hips (116 patients), mesenchymal stem cells (in the form of concentrated iliac crest bone marrow) were injected through a core decompression tract into the area of necrosis. ${ }^{23}$ Patients with early (precollapse) disease had excellent results at 5 years of clinical follow-up, with only nine of 145 hips requiring THA. ${ }^{23}$ However, amongst patients who had Stage III or greater disease at the time of therapeutic intervention, over 
half (25 of 44) hips required THA during the same time period. ${ }^{23}$ The authors of that study were also able to show that the amount of mesenchymal stem cells injected as well as the underlying etiology of AVN were related to progression of disease. Patients with lower stem cell concentrations (measured by colony-forming units in vitro) or a history of organ transplantation, alcohol use, or corticosteroid exposure were at increased risk of disease progression. ${ }^{23}$

The above group of patients was included in a recent retrospective review of concentrated bone marrow as a treatment for AVN. ${ }^{22}$ After an average follow-up of 13 years, it was found that 94 of 534 (17\%) hips progressed to THA. ${ }^{22}$ Patients in this group had a significantly increased Harris Hip Score and a decrease in the size of the necrotic lesion on MRI. Sixty-nine patients $(18 \%)$ in this group also had complete resolution of their necrotic lesion on MRI. ${ }^{22}$ The rate of progression to THA in this large study is similar to that previously reported. ${ }^{24}$ Similarly, they found that a majority of patients experience significant pain relief following injection of concentrated bone marrow into the necrotic femoral head. ${ }^{24}$

Since the original work by Hernigou and Beaujean, ${ }^{23}$ four studies have prospectively analyzed the use of core decompression alone and core decompression with autologous bone marrow (CDBM, Table 3). The first such study was performed in 2004 and compared patients with precollapse AVN (stage $1-2 \mathrm{AVN}) .{ }^{25}$ In this investigation, eight hips were treated with core decompression and ten hips received CDBM. At 2-year follow-up, the CDBM group had a significant decrease in pain $(P=0.021)$, with significant improvement in Western Ontario and McMaster/Lequesne osteoarthritis indices. ${ }^{25}$ Likewise, the size of the AVN lesion at the femoral head decreased significantly in the CDBM group from $15.6 \%$ preoperative to $10.1 \%$ at final follow-up. In terms of disease progression, five of eight hips in the core decompression group collapsed whereas only one of ten in the CDBM group collapsed. ${ }^{25}$ The results of this study have been carried out to 5 years of clinical follow-up, with the addition of three patients in each group. ${ }^{26}$ At the 5-year time point, eight of eleven hips in the core decompression group have fractured and collapsed, while only three of 13 hips in the CDBM have collapsed. ${ }^{26}$ Similarly, in another small study of 14 hips that underwent core decompression or CDBM, use of CDBM was found to be associated with significant improvement in the patient's Harris Hip Score and area of femoral head necrosis $(P<0.05)$, with no cases of collapse documented in the CDBM group. ${ }^{27}$

Recent larger prospective trials have been completed, and their results are promising and comparable with those of previous smaller studies. ${ }^{28}$ In one investigation of 25 hips treated with core decompression and 26 hips treated with CDBM, there was a significant improvement in Harris Hip Scores between the CDBM core decompression groups. ${ }^{28}$ To refine further the identification of which patients may benefit the most from stem cell therapy, the authors noted that patients in the CDBM group with poor preoperative Harris Hip Scores, X-ray changes, and edema or effusion on MRI had better results compared with similar patients in the core decompression group. ${ }^{28}$ In the largest study, 100 patients underwent core decompression (51 hips) or CDBM (53 hips). In the core decompression group, ten patients progressed and eventually required THA or a vascularized fibular graft, while only two hips in the CDBM group required a vascularized fibular graft. ${ }^{13}$ The findings of this study are consistent with those of smaller investigations demonstrating that patients

Table 3 Use of stem cells as treatment for avascular necrosis of the femoral head

\begin{tabular}{|c|c|c|c|c|c|c|}
\hline & $\begin{array}{l}\text { Number } \\
\text { of hips }\end{array}$ & $\begin{array}{l}\text { Mean number } \\
\text { of leukocytes } \\
\text { injected }\end{array}$ & $\begin{array}{l}\text { Average stem } \\
\text { cells per CFU } \\
\text { injected (cells) }\end{array}$ & $\begin{array}{l}\text { Percent } \\
\text { progression } \\
\text { to THA }\end{array}$ & $\begin{array}{l}\text { Percent decrease } \\
\text { in size of lesion } \\
\text { on MRI }\end{array}$ & $\begin{array}{l}\text { Risk factors } \\
\text { for progression }\end{array}$ \\
\hline $\begin{array}{l}\text { Hernigou and } \\
\text { Beaujean }^{23}\end{array}$ & 189 & $16.4 \pm 11.5 \times 10^{6}$ & $25 \times 10^{3}$ & 6 & - & $\begin{array}{l}\text { - Corticosteroids } \\
\text { - Previous organ transplant } \\
\text { - Femoral head collapse }\end{array}$ \\
\hline Hernigou et $\mathrm{al}^{22}$ & 534 & - & $24 \times 10^{3}$ & 17.6 & $46 \%$ & $\begin{array}{l}\text { - Low number of stem } \\
\text { cells injected }\end{array}$ \\
\hline Gangji et $\mathrm{al}^{25}$ & 13 & $2.0 \pm 0.3 \times 10^{9}$ & $92 \pm 9 / 10^{7}$ & - & $33 \%$ & - \\
\hline Gangi et $\mathrm{al}^{26}$ & 13 & $1.9 \pm 0.2 \times 10^{9}$ & $92 \pm 22.4 \times 10^{7}$ & 15 & $42 \%$ & - \\
\hline Sen et $\mathrm{al}^{28}$ & 26 & $5 \times 10^{8}$ & - & - & - & $\begin{array}{l}\text { - High Harris Hip Score on } \\
\text { presentation } \\
\text { - Lack of effusion or edema } \\
\text { on preoperative MRI }\end{array}$ \\
\hline Zhao et $\mathrm{al}^{13}$ & 53 & $2 \times 10^{6}$ & - & 4 & Up to $75 \%$ & - \\
\hline
\end{tabular}

Abbreviations: CFU, colony-forming units; MRI, magnetic resonance imaging; THA, total hip arthroplasty. 
treated with CDBM achieved significantly higher Harris Hip Scores at final follow-up.

Although these initial results have been promising, a recent study showed no difference in outcome with regard to core decompression versus multiple drilling of the AVN lesion and augmenting the procedure with concentrated bone marrow. ${ }^{29}$ It has been demonstrated that mesenchymal stem cells may not be able to survive in the necrotic lesions. ${ }^{30,31}$ However, previous studies in patients with AVN of the femoral head have shown that labeled stem cells stay within the necrotic lesion, and are able to expand and survive in the avascular environment for up to 12 weeks following adequate decompression. ${ }^{26,32}$ In order to explain the results of the study by Lim et al, ${ }^{29}$ it may be that the decompression obtained was not adequate to induce a complete healing response.

One other factor that has been shown to influence healing of necrotic lesions in the femoral head has been the number of stem cells injected. ${ }^{22,23}$ Ex vivo amplification of the iliac crest stem cells has been proposed in order to increase the number of stem cells injected. ${ }^{33,34}$ In both of these studies, the authors found that mesenchymal stem cells isolated from the iliac crest can be successfully expanded in an ex vivo setting and transplanted to the area of osteonecrosis. The authors found that no patient has had a progression in the size or stage of their AVN lesions. ${ }^{33,34}$

Use of bone marrow for the treatment of AVN has also been attempted in osteonecrosis of the knee. ${ }^{35}$ In a small study, the investigators debrided the areas of AVN in the femoral condyles, and then used iliac crest bone marrow along with a bone matrix to fill the lesions. ${ }^{35}$ At 2 years of clinical follow-up, they noted no progression in the size of the necrotic lesions and all patients had an increase in their American Knee Society scores, as well as a decrease in pain. ${ }^{35}$

A small case series has been published looking at injecting adipose-derived mesenchymal stem cells directly into the hip joints of patients with AVN of the femoral head. ${ }^{36}$ The patients in this study noted a reduction in pain that coincided with a decrease in the necrotic volume within the femoral head. ${ }^{36}$ Although this study shows promise by using a plentiful and easily accessible source of mesenchymal stem cells, the results of the study remain under debate. ${ }^{37}$

\section{Our surgical technique}

Patients are selected to undergo minimally invasive hip decompression augmented by concentrated bone marrow aspirate if they meet our inclusion criteria (Table 4). The procedure is only performed in patients with stage 0,1 , or 2 AVN
Table 4 Indications for stem cell treatment

Indications for surgery

- Patients with symptomatic stage I or 2 avascular necrosis of the femoral head

- Patients with bilateral avascular necrosis where one hip is symptomatic and the other hip is stage 0 and asymptomatic

- Patients with large ( $>30 \%)$ asymptomatic lesions found on magnetic resonance imaging

Contraindications to surgery

- Patients with stage 3 or higher avascular necrosis of the femoral head

- Patients with rapidly progressive avascular necrosis

- Patients with active or chronic infection

of the femoral head according to the Steinberg classification (Figure 1A). ${ }^{21}$ In order to obtain mesenchymal stem cells, a small (2-3 mm) incision is made over the anterior iliac crest. A small trochar (MarrowStim, Biomet Biologics, Warsaw, IN, USA) is inserted into the iliac crest and bone marrow is aspirated. The bone marrow is then concentrated using a Bio-Cue System (Biomet Biologics), whereby $60 \mathrm{cc}$ of bone marrow is concentrated $10 \times$ to produce $6 \mathrm{~mL}$ of concentrated bone marrow. Typically, $12 \mathrm{~mL}$ of concentrated bone marrow is used for each hip. During this time, $120 \mathrm{~mL}$ of blood is obtained to produce $12 \mathrm{~mL}$ of platelet-rich plasma, which serves as a cell growth adjuvant.

\section{Hip decompression and injection of concentrated bone marrow}

During the time in which the bone marrow and peripheral blood is being concentrated and processed, we start the hip decompression. An incision is made over the lateral aspect of the femur at the level of the vastus ridge. When the ideal starting point has been obtained, just above the level of the lesser trochanter and distal to the vastus ridge, a $6 \mathrm{~mm}$ trochar is advanced with gentle tapping using a mallet under fluoroscopy, to end "in" the necrotic lesion. Correct trochar

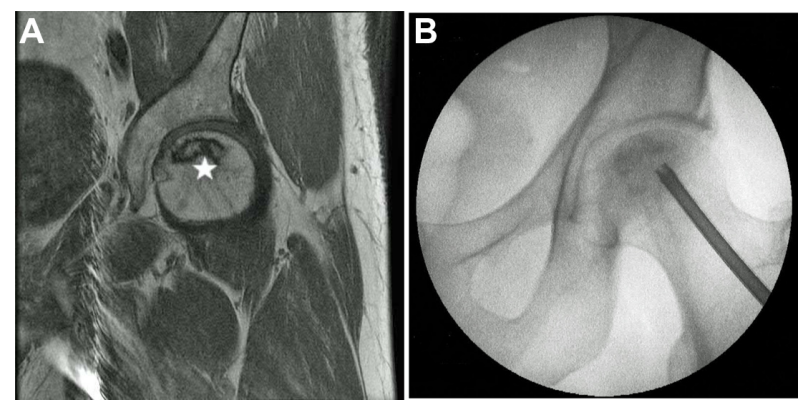

Figure I Magnetic resonance image from a patient with an avascular necrosis lesion (star) at the femoral head (A). Intraoperative radiograph of the patient undergoing minimally invasive core decompression with injection of autologous concentrated bone marrow aspirate $(\mathbf{B})$. 
positioning is then confirmed using fluoroscopy (Figure 1B). The inner core of the trochar is removed, leaving a hollow trochar in place. Once optimal positioning has been achieved, the concentrated bone marrow and platelet-rich plasma are combined and injected through the trochar into the necrotic lesion of the femoral head. When the injection has been completed, the tract is then packed with autologous cancellous bone to prevent back flow of the concentrated bone marrow and platelet-rich plasma products.

\section{Postoperative care}

This is an outpatient surgical procedure, after which all patients are discharged home and allowed to weight-bear as tolerated with crutches for 2 weeks. We have found that a small number of patients initially have an increase in pain after the injection; however, this pain is typically short-lived, with most patients reporting significant pain relief within a few weeks.

Hip decompression with injection of concentrated bone marrow and platelet-rich plasma has been performed on 73 hips at our institution. Over the follow-up period (average 17 months), 16 hips (21\%) have progressed to further stages of osteonecrosis, ultimately requiring total hip replacement. ${ }^{24}$ Although some patients have progressed to needing THA, others have had complete resolution of their symptoms as well as their lesions on MRI (Figure 2). Importantly, there have been no significant complications in any patient undergoing this procedure. Significant pain relief, based on the visual analog scale, has been reported in 60 patients $(86 \%)$, while the remainder reported little or no pain relief. ${ }^{24}$

In conclusion, the use of core decompression combined with mesenchymal stem cells in the form of concentrated bone marrow can provide significant pain relief, improvement
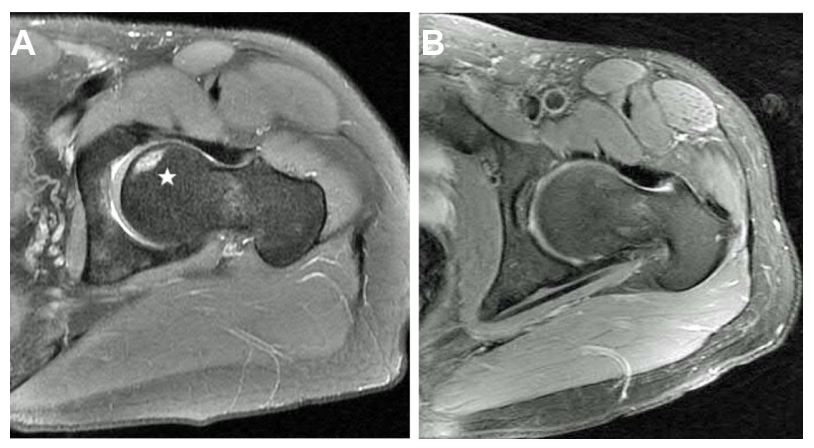

Figure 2 Preoperative magnetic resonance image (A) from a patient with an avascular necrosis lesion at the femoral head (star). The patient underwent minimally invasive core decompression with injection of autologous concentrated bone marrow aspirate and noted a significant reduction and pain. Follow-up magnetic resonance imaging 2 years following decompression and concentrated bone marrow injection showed complete resolution of the avascular necrosis lesion (B). in function, and ultimately halt the progression of AVN of the femoral head. Using this minimally invasive regenerative hip preservation therapy, young patients can hopefully avoid the need for THA and be able to return to normal function and activities of daily living.

\section{Disclosure}

The authors have received research support from Biomet Biologics (Warsaw, IN, USA).

\section{References}

1. Herndon JH, Aufranc OE. Avascular necrosis of the femoral head in the adult. A review of its incidence in a variety of conditions. Clin Orthop Relat Res. 1972;86:43-62.

2. Mwale F, Wang H, Johnson AJ, Mont MA, Antoniou J. Abnormal vascular endothelial growth factor expression in mesenchymal stem cells from both osteonecrotic and osteoarthritic hips. Bull NYU Hosp Jt Dis. 2011;69 Suppl 1:S56-S61.

3. Lavernia CJ, Sierra RJ, Grieco FR. Osteonecrosis of the femoral head. J Am Acad Orthop Surg. 1999;7:250-261.

4. Gangji V, Hauzeur JP. Treating osteonecrosis with autologous bone marrow cells. Skeletal Radiol. 2010;39:209-211.

5. Hernigou P, Bachir D, Galacteros F. The natural history of symptomatic osteonecrosis in adults with sickle-cell disease. J Bone Joint Surg Am. 2003;85-A:500-504.

6. Hernigou P, Poignard A, Nogier A, Manicom O. Fate of very small asymptomatic stage-I osteonecrotic lesions of the hip. $J$ Bone Joint Surg Am. 2004;86-A:2589-2593.

7. Hernigou P, Habibi A, Bachir D, Galacteros F. The natural history of asymptomatic osteonecrosis of the femoral head in adults with sickle cell disease. J Bone Joint Surg Am. 2006;88:2565-2572.

8. Cheng EY, Thongtrangan I, Laorr A, Saleh KJ. Spontaneous resolution of osteonecrosis of the femoral head. J Bone Joint Surg Am. 2004; 86-A:2594-2599.

9. Bozic KJ, Zurakowski D, Thornhill TS. Survivorship analysis of hips treated with core decompression for nontraumatic osteonecrosis of the femoral head. J Bone Joint Surg Am. 1999;81:200-209.

10. Iorio R, Healy WL, Abramowitz AJ, Pfeifer BA. Clinical outcome and survivorship analysis of core decompression for early osteonecrosis of the femoral head. J Arthroplasty. 1998;13:34-41.

11. Ito H, Matsuno T, Omizu N, Aoki Y, Minami A. Mid-term prognosis of non-traumatic osteonecrosis of the femoral head. J Bone Joint Surg Br. 2003;85:796-801.

12. Aldridge JM 3rd, Urbaniak JR. Avascular necrosis of the femoral head: etiology, pathophysiology, classification, and current treatment guidelines. Am J Orthop (Belle Mead NJ). 2004;33:327-332.

13. Zhao D, Cui D, Wang B, et al. Treatment of early stage osteonecrosis of the femoral head with autologous implantation of bone marrow-derived and cultured mesenchymal stem cells. Bone. 2012;50:325-330.

14. Jones LC, Mont MA, Le TB, et al. Procoagulants and osteonecrosis. J Rheumatol. 2003;30:783-791.

15. Hungerford DS. Pathogenesis of ischemic necrosis of the femoral head. Instr Course Lect. 1983;32:252-260.

16. Liu YF, Chen WM, Lin YF, et al. Type II collagen gene variants and inherited osteonecrosis of the femoral head. N Engl J Med. 2005;352: 2294-2301.

17. Mont MA, Hungerford DS. Non-traumatic avascular necrosis of the femoral head. J Bone Joint Surg Am. 1995;77:459-474.

18. Mont MA, Jones LC, Einhorn TA, Hungerford DS, Reddi AH. Osteonecrosis of the femoral head. Potential treatment with growth and differentiation factors. Clin Orthop Relat Res. 1998;355 Suppl:S314-S335.

19. Ficat RP. Idiopathic bone necrosis of the femoral head. Early diagnosis and treatment. J Bone Joint Surg Br. 1985;67:3-9. 
20. Kerboul M, Thomine J, Postel M, Merle d'Aubigné R. The conservative surgical treatment of idiopathic aseptic necrosis of the femoral head. J Bone Joint Surg Br. 1974;56:291-296.

21. Steinberg ME, Hayken GD, Steinberg DR. A quantitative system for staging avascular necrosis. J Bone Joint Surg Br. 1995;77:34-41.

22. Hernigou P, Poignard A, Zilber S, Rouard H. Cell therapy of hip osteonecrosis with autologous bone marrow grafting. Indian J Orthop. 2009;43:40-45.

23. Hernigou P, Beaujean F. Treatment of osteonecrosis with autologous bone marrow grafting. Clin Orthop Relat Res. 2002;405:14-23.

24. Martin JR, Houdek MT, Sierra RJ. Use of concentrated bone marrow aspirate and platelet rich plasma during minimally invasive decompression of the femoral head in the treatment of osteonecrosis. Croat Med J. 2013;54:219-224.

25. Gangji V, Hauzeur JP, Matos C, De Maertelaer V, Toungouz M, Lambermont M. Treatment of osteonecrosis of the femoral head with implantation of autologous bone-marrow cells. A pilot study. J Bone Joint Surg Am. 2004;86-A:1153-1160.

26. Gangji V, De Maertelaer V, Hauzeur JP. Autologous bone marrow cell implantation in the treatment of non-traumatic osteonecrosis of the femoral head: five year follow-up of a prospective controlled study. Bone. 2011;49:1005-1009.

27. Chang T, Tang K, Tao X, et al. [Treatment of early avascular necrosis of femoral head by core decompression combined with autologous bone marrow mesenchymal stem cells transplantation]. Zhongguo Xiu Fu Chong Jian Wai Ke Za Zhi. 2010;24:739-743. Chinese.

28. Sen RK, Tripathy SK, Aggarwal S, Marwaha N, Sharma RR, Khandelwal N. Early results of core decompression and autologous bone marrow mononuclear cells instillation in femoral head osteonecrosis: a randomized control study. J Arthroplasty. 2012;27:679-686.
29. Lim YW, Kim YS, Lee JW, Kwon SY. Stem cell implantation for osteonecrosis of the femoral head. Exp Mol Med. 2013;45:e61.

30. Potier E, Ferreira E, Andriamanalijaona R, et al. Hypoxia affects mesenchymal stromal cell osteogenic differentiation and angiogenic factor expression. Bone. 2007;40:1078-1087.

31. Potier E, Ferreira E, Meunier A, Sedel L, Logeart-Avramoglou D, Petite H. Prolonged hypoxia concomitant with serum deprivation induces massive human mesenchymal stem cell death. Tissue Eng. 2007;13:1325-1331.

32. Yan Z, Hang D, Guo C, Chen Z. Fate of mesenchymal stem cells transplanted to osteonecrosis of femoral head. J Orthop Res. 2009;27:442-446.

33. Müller I, Vaegler M, Holzwarth C, et al. Secretion of angiogenic proteins by human multipotent mesenchymal stromal cells and their clinical potential in the treatment of avascular osteonecrosis. Leukemia. 2008;22:2054-2061.

34. Rackwitz L, Eden L, Reppenhagen S, et al. Stem cell- and growth factor-based regenerative therapies for avascular necrosis of the femoral head. Stem Cell Res Ther. 2012;3:7.

35. Lee K, Goodman SB. Cell therapy for secondary osteonecrosis of the femoral condyles using the Cellect DBM System: a preliminary report. J Arthroplasty. 2009;24:43-48.

36. Pak J. Autologous adipose tissue-derived stem cells induce persistent bone-like tissue in osteonecrotic femoral heads. Pain Physician. 2012;15:75-85.

37. Kim HJ. Autologous adipose tissue-derived stem cells induce persistent bone-like tissue in osteonecrotic femoral heads: not bone-like, but fatlike tissue. Pain Physician. 2012;15:E749.
Stem Cells and Cloning: Advances and Applications

\section{Publish your work in this journal}

Stem Cells and Cloning: Advances and Applications is an international, peer-reviewed, open access journal. Areas of interest in stem cell research include: Embryonic stem cells; Adult stem cells; Blastocysts; Cordblood stem cells; Stem cell transformation and culture; Therapeutic cloning; Umbilical cord blood and bone marrow cells; Laboratory,

\section{Dovepress}

animal and human therapeutic studies; Philosophical and ethical issues related to stem cell research. This journal is indexed on CAS. The manuscript management system is completely online and includes a quick and fair peer-review system. Visit http://www.dovepress.com/ testimonials.php to read real quotes from published authors. 